\title{
The risk of carbon leakage in global climate agreements
}

\author{
Tobias Nielsen ${ }^{1,4} \cdot$ Nicolai Baumert ${ }^{2}$ (ID $\cdot$ Astrid Kander² $\cdot$ Magnus Jiborn ${ }^{2}$. \\ Viktoras Kulionis ${ }^{2,3}$
}

Accepted: 3 September 2020 / Published online: 16 September 2020

(c) The Author(s) 2020

\begin{abstract}
Although climate change and international trade are interdependent, policy-makers often address the two topics separately. This may inhibit progress at the intersection of climate change and trade and could present a serious constraint for global climate action. One key risk is carbon leakage through emission outsourcing, i.e. reductions in emissions in countries with rigorous climate policies being offset by increased emissions in countries with less stringent policies. We first analyze the Paris Agreement's nationally determined contributions (NDC) and investigate how carbon leakage is addressed. We find that the risk of carbon leakage is insufficiently accounted for in these documents. Then, we apply a novel quantitative approach (Jiborn et al., 2018; Baumert et al., 2019) to analyze trends in carbon outsourcing related to a previous international climate regime - the Kyoto Protocol-in order to assess whether reported emission reductions were offset by carbon outsourcing in the past. Our results for 2000-2014 show a more nuanced picture of carbon leakage during the Kyoto Protocol than previous studies have reported. Carbon outsourcing from developed to developing countries was dominated by the USA outsourcing to China, while the evidence for other developed countries was mixed. Against conventional wisdom, we find that, in general, countries that stayed committed to their Kyoto Protocol emission targets were either only minor carbon outsourcers or actually even insourcers-although the trend was slightly negative-indicating that binding emissions targets do not necessarily lead to carbon outsourcing. We argue that multiple carbon monitoring approaches are needed to reduce the risk of carbon leakage.
\end{abstract}

Keywords Carbon leakage $\cdot$ Paris agreement $\cdot$ Kyoto protocol $\cdot$ Emission outsourcing · Climate policy $\cdot$ Carbon monitoring

Electronic supplementary material The online version of this article (https://doi.org/10.1007/s1078 4-020-09507-2) contains supplementary material, which is available to authorized users.

Nicolai Baumert

nicolai.baumert@ekh.lu.se

1 Department of Political Science, Lund University, Box 52, 22100 Lund, Sweden

2 Department of Economic History, Lund University, Box 7083, 22007 Lund, Sweden

3 Institute of Environmental Engineering, ETH Zürich, 8093 Zürich, Switzerland

4 IVL Swedish Environmental Research Institute, Nordenskiöldsgatan 24, 21119 Malmö, Sweden 


\section{Introduction}

International trade and climate change policy are intrinsically linked, yet often dealt with in separate silos (Betsill et al. 2015; Bhagwati and Mavroidis 2007). Climate negotiations under the UN Framework Convention on Climate Change (UNFCCC) focus on national climate action and the distribution of responsibilities between countries, but pay little attention to effects of international trade. Yet, emissions embodied in trade amount to roughly $25 \%$ of global greenhouse gas (GHG) emissions (Peters et al. 2011; Wood et al. 2018). Negotiations within the World Trade Organization (WTO) focus on trade regulations and liberalization without much attention to how such measures interact with climate goals. This sharp separation of responsibilities may inhibit progress on issues that lie in the intersection between climate change and trade and thereby presents a serious constraint for global climate action (Bacchus 2016).

International trade has the potential to contribute to a carbon efficient allocation of global production resources and may thereby facilitate cost-efficient carbon mitigation. Nevertheless, it can also undermine ambitious climate goals if carbon intensive production is outsourced (deliberately or not) to countries with less stringent mitigation policies. Conversely, widespread suspicion of large-scale carbon emission outsourcing - or carbon leakage - may undermine support for ambitious climate policies (Jiborn et al. 2018). Our study focuses on all carbon leakage across countries (weak carbon leakage) and is not limited to emission outsourcing that is directly caused by differences in climate policy stringency (strong carbon leakage).

Throughout the paper, we use the terms carbon leakage and (carbon) emission outsourcing interchangeably. We will use these terms such that a country is outsourcing carbon emissions if its exports and imports lead to lower domestic emissions and higher emissions abroad, than would be the case on a no-trade scenario with the same consumption.

The IPCC 4th Assessment Report (Parry et al. 2007) identifies three possible mechanisms by which carbon leakage can occur: (1) emission intensive production may be outsourced to non-constrained areas through changes in international trade patterns; (2) falling prices of fossil fuels due to reduced demand in some areas may lead to increased use in other areas; and (3) changes in terms of trade may lead to increased income and hence greater energy demand in non-constrained areas. This paper focuses on the role of emission outsourcing via international trade (cf. Kander et al. 2015). Emission outsourcing does not necessarily imply that entire industries are moved abroad, but rather that the balance of heavy and light production in export and import changes in such a way that potential domestic carbon reductions may (partially) be offset by increases abroad.

The major contribution of this paper is the combination of a qualitative analysis of the extent to which emission outsourcing was addressed within the nationally determined contributions (NDCs) of the 2015 Paris Agreement and a quantitative analysis of the magnitude of emission outsourcing during the period of an earlier climate agreement, namely the Kyoto Protocol. This may indicate whether the risk of carbon outsourcing in times of increased international efforts to combat climate change is-based on past experiencesufficiently reflected in countries' NDCs.

The sealing of the Paris Agreement in 2015 marks an important step forward in global efforts to combat climate change. For the first time, the majority of countries in the world (and not just developed nations) have committed to carbon reductions and limitations, albeit voluntarily. This could potentially reduce the risk of carbon leakage compared to previous agreements where only developed countries committed to carbon reductions. 
Under the 1997 Kyoto Protocol (KP), carbon leakage was commonly defined as emissions reductions in countries with binding emissions targets according to the Protocol—so called Annex B countries-being offset by increased emissions in non-Annex B countries without such binding commitments. Although countries with binding targets collectively reduced their emissions during the period covered by the Protocol, global emissions continued to increase, partly due to increased production in non-Annex B countries for export to Annex B countries (Aichele and Felbermayr 2015; Wyckoff and Roop 1994; Peters and Hertwich 2008; Jakob et al. 2013).

However, under the Paris Agreement, each country still defines its own reduction targets and policies to achieve them. Since the NDCs vary, not only in ambition but also in types of target, the risk of carbon leakage - from countries with absolute reduction targets (i.e. most developed countries) to countries with relative reduction targets (i.e. most developing countries) ${ }^{1}$-remains an important issue. Similarly, avoiding carbon leakage is relevant when it comes to parties cooperating on fulfilling their NDC's through Article 6 (Müller and Michaelowa 2019).

In this paper, we address the issue of carbon leakage in three ways. First, we analyze the NDC submissions under the current climate agreement (i.e. the 2015 Paris Agreement) and investigate how issues related to emission flows in trade and carbon outsourcing are addressed. Second, we use recently published emission data for 2000-2014 and employ a novel method to analyze carbon outsourcing trends of countries with and without binding targets under the Kyoto Protocol. This allows us to assess whether, and to what extent, emission reductions were offset by carbon leakage in the major past climate agreement. Third, we discuss the potential effects of emission outsourcing and the need for multiple carbon monitoring approaches going forward.

\section{Methodology}

\subsection{Qualitative methods}

This paper combines qualitative and quantitative approaches. The qualitative part of the analysis consists of a systematic text analysis of NDCs to reveal how trade and carbon outsourcing are approached in the Paris Agreement. NDCs are increasingly being used to analyze countries' positions or the role of certain issue areas in the climate negotiations (cf. Pauw et al. 2016; Charlery and Trærup 2019). Manual coding was used as this allows a reflective iterative process between the data material and coding (cf. Brandi 2017; Tørstad and Sælen 2018). This enables a more inductive approach of how countries perceived the role of trade in the Paris Agreement, rather than a purely deductive approach (Tørstad and Sælen 2018). It also reduces 'noise' by ensuring that, for example, 'Minister of Trade' was not counted as part of the amount of times the term 'trade' appeared in the NDC submissions. The main limitation of manual coding is that it is often considered less reliable than automated coding.

\footnotetext{
1 Such relative emission reduction targets are defined in comparison with projections of historical emission trends or in relation to GDP.
} 
NDCs $^{2}$ submitted from February 2015 to February 2017 were included in the study. The findings were cross-checked with interactive tools for NDC analysis, including NDC explorer (Pauw et al. 2016) and The Climate Access Indicators Tool (CAIT). In addition, we conducted field observations and eight open-ended interviews at Paris COP21 in 2015 and Marrakesh COP22 in 2016. The following interviews were included in the study: two delegates from developing countries, one delegate from a developed country, three NGO representatives with extensive experience in the Monitoring, Reporting and Verification (MRV) debates, and two experts on carbon monitoring. These interviews were used to gain further insights into the analysis of the data and were selected to represent a broad range of stakeholders.

NDCs do not represent hard national policies, but should rather be seen as political documents providing political statements and reflections of prioritizations and responsibilities of mitigation within the climate change regime (Winkler et al. 2017). The fact that the NDCs point to a gap between trade and climate does not, on its own, rule out that countries touch upon these issues in other forums or policy documents. However, countries' future climate action are largely shaped by their NDCs, and thus, they do provide key insights into how the issue of carbon leakage is addressed in relation to countries' climate actions (Brandi 2017). While NDCs disclose neither the full extent of countries' trade policies, nor their interlinkages with climate change, they do represent an important indicator for how countries perceive the role of trade (and carbon outsourcing) within the climate change process (Chan et al. 2016).

\subsection{Quantitative methods}

In order to establish an improved understanding of the extent, to which carbon outsourcing through global trade may undermine climate mitigation policies, we quantify emission outsourcing and assess whether there has previously been systematic outsourcing from countries with binding emission targets to countries without. Many such studies examine the spatial divide between emission generation and final consumption by using Multi-Region Input-Output analysis (Wiedmann 2009; Davis and Caldeira 2010; Peters et al. 2011). Such analysis disentangles the production stages of global value chains and thereby enables the tracing of production-related carbon emissions of final goods across the involved countries. Reallocating emissions to countries of final consumption may yield large differences when compared to each country's production-based emissions. However, structural outsourcing of emissions from developed nations as a consequence of having a domestic service economy and importing heavy industrial goods from abroad should not be confused with emissions transfers that result from differences between countries' technologies or energy systems (Jakob et al. 2013; Kander et al. 2015; Jiborn et al. 2018; Baumert et al. 2019).

For example, consider a country with near-zero emissions in its energy system, due to a large share of renewable and/or nuclear energy, and with a strong focus on energy heavy industrial goods in its exports, while imports mainly consist of light manufacture and services, largely from countries with less carbon efficient energy systems. Due

\footnotetext{
2 Initially, Intended Nationally Determined Contribution (INDC) was analyzed; however, an INDC is automatically turned into an NDC when a country ratifies the Paris Agreement, unless it communicates that it prefers to update the document first, which only very few parties have done.
} 
to the composition of exports and imports, the country is a large net exporter of energy embodied in traded goods. Moreover, since its exports replace energy heavy production elsewhere-where energy production is largely fossil fuel based-the net effect of its trade on emissions abroad is negative; its exports reduce foreign emissions more than the emissions generated in producing the goods that it imports. However, since energy embodied in its exports has near-zero emissions, this country could still have a negative balance of emissions embodied in trade (BEET). But exchanging energy heavy industrial goods for light manufacture cannot reasonably be classified as carbon outsourcing.

As another example, consider a case where a country over time replaces fossil fuels in its export industries with renewable energy. Suppose all other factors remain unchanged. This country would then reduce its production-based accounting (PBA) emissions during the period, but its BEET would also become more negative. Hence, if negative BEET is considered evidence of carbon outsourcing, the conclusion would be that part of the decrease in domestic emissions (PBA) were offset by increasing carbon outsourcing. Surely, that is not a reasonable interpretation.

The traditional concept of BEET is therefore not a reliable indicator of emission outsourcing. We employ the technology-adjusted balance of emissions embodied in trade (TBEET) developed by Kander et al. (2015) and Jiborn et al. (2018). This method harmonizes international differences in sectoral carbon intensities to isolate the impact of trade specialization and monetary trade balance on flows of (embodied) carbon emissions. The TBEET indicator describes the net balance of emissions traded by a country (group) after correcting for technology differences, which is a more adequate indicator of structural carbon outsourcing (see Supplementary Information for a more detailed elaboration on the TBEET measure). Applying this indicator to the second example above yields the result TBEET $=0$ for the regarded country, implying that the trade scenario does not involve carbon outsourcing.

Baumert et al. (2019) apply the TBEET approach to a global context by examining 40 countries included in the World Input-Output database-WIOD (Timmer et al. 2015). The authors find that roughly half of the observed imbalance in emissions embodied in trade was attributable to differences in technologies and energy systems. Jiborn et al. (2020) provided the results for 43 countries' emission responsibility according to technology-adjusted consumption-based accounting (TCBA) between 2000 and 2014 based on the 2016 release of WIOD as well as the environmental extension published by Corsatea et al (2019).

This paper brings the analysis further by analyzing these 43 countries' TBEET for the period 2000-2014, and focusing specifically on whether countries that had committed to the KP outsourced more emissions than countries that had not, to see whether an earlier climate agreement might have coincided with increased structural emission outsourcing. Moreover, the quantitative analysis is combined with qualitative insights from NDC text analysis.

Future studies could complement this paper by including data from other databases such as EXIOBASE3 (Stadler et al. 2018). We used WIOD, partly because EXIOBASE3 was unavailable during the data analysis, because WIOD can be used for comparative purposes with other similar studies, and since its corresponding environmental accounts have recently been updated (Corsatea et al. 2019). For further discussion on the potential limitations and uncertainties associated with carbon accounting, the use of different databases, and the TBEET indicator, see Supplementary Information 1 and 2. 


\section{Results}

\subsection{Carbon outsourcing in the Paris Agreement NDCs}

Direct references to carbon outsourcing were not found in any of the 163 NDCs sampled. However, a number of related aspects were analyzed, including references to: types of targets, international trade, consumption, leakage, and carbon footprint. These are analyzed in the sections below with an overview in Table 1 and overall conclusions at the end.

\subsubsection{Types of targets}

All developed countries (commonly referred to as Annex I countries in the UNFCCC) have submitted absolute targets, i.e. targets of absolute emissions reductions compared to emissions in a historical benchmark year. Brazil is one of few large developing country emitters that have submitted absolute targets. Most developing countries have instead submitted relative targets, either as reductions below BAU, ${ }^{3}$ carbon intensity target (aggregate carbon emitted per unit of GDP), or they have set a year of peak emissions (peaking targets). The rest of the submitted targets come in the form of "policies and actions" or "adaptation with mitigation co-benefits," so with no clear quantitative emission goals. In addition, most developing countries have presented both unconditional and conditional targets. Conditional targets tend to be more ambitious and dependent on external support, such as finance or technology transfer from developed countries. Besides varying types of targets, the scale of targets also varies from covering economy-wide emissions to sector (usually energy) specific emissions.

Considering the four largest emitters, we see that China's ${ }^{4}$ and India's 2030 targets are to lower $\mathrm{CO}_{2}$ emissions per unit of GDP by 60-65\% and 33-35\%, respectively, compared to the 2005 level. The EU's target is to lower its $1990 \mathrm{GHG}$ emissions by $40 \%$ by 2030 , while the USA's target is to reduce its GHG emissions 26-28\% below their 2005 levels by 2025 .

Assuming an average annual GDP growth rate of $4 \%$ in China and India from today until 2030 -a conservative assumption given that the average growth rates since 2005 have been $9 \%$ for China and $7.5 \%$ for India,$^{5}$ these economies will be more than four times larger in 2030 than in 2005. This in turn means that China's carbon emissions could increase by $70 \%$ in absolute numbers (by 2030, the year they aim to reach peak $\mathrm{CO}_{2}$ emissions), and India's could more than double and still be in line with their NDCs. The commitments made by these two countries thereby admit for an absolute increase in emissions twice as large as the combined reductions committed to by the EU and the USA. Consequently, submitted NDCs could leave room for substantial carbon outsourcing from countries with absolute targets to countries with relative ones, which represents a real risk for the success of climate mitigation.

\footnotetext{
3 BAU refers to a "baseline" or "business-as-usual" level of fossil-fuel consumption in a country, against which any (unconditional or conditional) target can be compared or measured. There is a large degree of flexibility, and often little transparency, in how countries decide to set their BAU scenario.

${ }^{4}$ China also has a target to reach peak $\mathrm{CO}_{2}$ emissions by 2030.

5 The figures are based on World Bank data: https://data.worldbank.org/indicator/ny.gdp.mktp.kd.zg.
} 


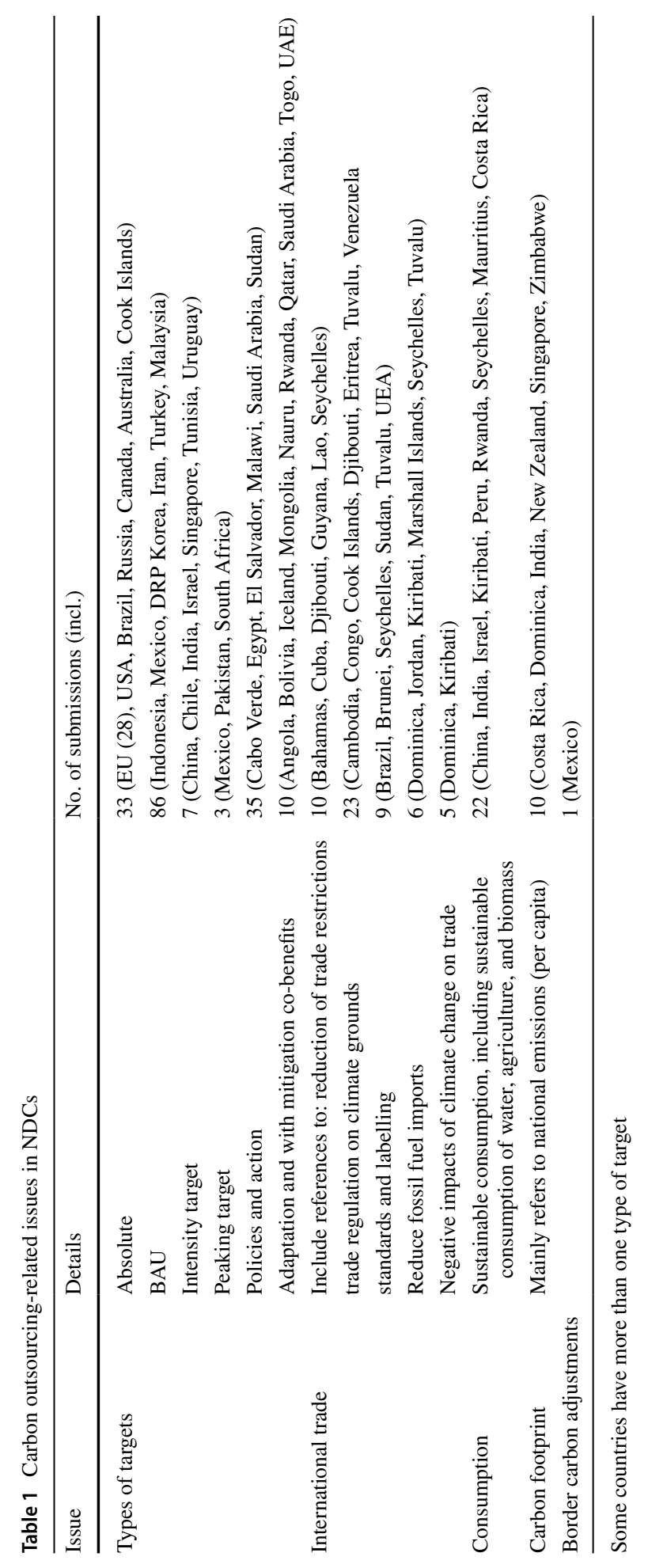




\subsubsection{International trade}

Thirty-six of the NDCs include specific trade elements that are geared towards fostering mitigation. Interestingly, the largest importers (e.g. the USA) and exporters (e.g. China) of embodied carbon do not include trade in their NDCs, while countries (e.g. Cambodia, Cook Islands, and Venezuela) that are highly vulnerable to the impacts of climate change and have a high degree of trade openness have included more trade elements in their NDCs (see also Chan et al. 2016; Brandi 2017). The most common references to trade are: reducing trade barriers to stimulate diffusion of climate friendly goods (ten countries), regulating trade on climate grounds (23 countries), promoting transparency and awareness among producers and consumer through labelling (nine countries), and negative effects of climate change on exports (five countries). We found no direct references to countries mentioning the risks of carbon outsourcing or leakage. Of course, such risks could still be approached in other policy forums, but countries do not seem to perceive emissions embodied in trade as a risk relevant to the UNFCCC process. Reasons for this are likely to include that trade in general is seen as a sensitive issue at the UNFCCC and that dealing with the issue of carbon outsourcing is perceived to add to the complexity of the negotiations particularly due to the clear overlap with WTO-related policy issues.

\subsubsection{Consumption}

Consumption relates to carbon outsourcing as countries' domestic demands may affect production patterns abroad, e.g. the USA and China. The UNFCCC does not have the mandate to interfere with consumption patterns in individual countries. However, preventing one's climate action from increasing emissions elsewhere would be a meaningful aspirational goal for countries. Moreover, at the very least the external impact of one's consumption should be discussed in the UNFCCC to get more comprehensive action (Harris and Symons 2013).

In total, 44 submitted NDCs mention 'consumption,' but mainly when referring to energy consumption. Of these, 22 countries, including China and India but surprisingly no developed countries, mention sustainable consumption as part of their domestic mitigation efforts. These references to sustainable consumption do not include a consideration of the effects that a country's consumption pattern may have on other countries. In general, there is little debate at the UNFCCC on consumption patterns and the measurement of consumption-based accounting (based on observations and interviews at COP21 and COP22). ${ }^{6}$ Even countries that are major exporters of embodied emissions have shown little interest in consumption-based accounting, and in estimating emissions linked to traded goods, other than electricity (Harris and Symons 2013). Key barriers to introducing a consumption-based approach of measuring emission responsibility include a perceived increase in complexity, perceived lack of data, fears that reduced consumption may impact economic growth negatively, and countries' reluctance to take on responsibility for emissions happening abroad that they cannot directly control. The debate over consumption and consumption-based accounting has, however, been picked up by non-state actors. Several NGOs argue that consumption-based emission levels should be accounted for in the negotiations, and several

\footnotetext{
${ }^{6}$ Consumption-based accounting (CBA) is equal to PBA, plus imports, minus exports of embodied emissions. When compared to PBA, they can provide an indication of whether a country is outsourcing its emissions.
} 
businesses have begun analyzing emissions related to different stages of their supply-chains (Chan et al. 2016; Peters 2008).

\subsubsection{Carbon border adjustments}

One measure to address carbon leakage, which has been the topic of much recent debate, is carbon border adjustments (Ladly 2012). This measure-often accompanied by either a domestic carbon tax or a cap-and-trade scheme-would try and level the playing field between domestic producers facing costly climate restrictions while foreign producers may only be subject to very few such restrictions. Proponents see carbon border adjustments as a key tool to mitigate the risk of carbon leakage, to protect local low-carbon production, and boost climate-smart trade (Mehling et al. 2018; Arroyo-Currás et al. 2015). Others have criticized the idea as incompatible with WTO rules, potentially leading to trade wars, and having only limited impact on global climate gains (Balistreri et al. 2015; Jakob et al. 2013). So far, carbon border adjustments have only been implemented to a limited extend, ${ }^{7}$ and Mexico is the only country that mentions them in its NDCs. Nevertheless, political momentum may be shifting. The 2019 European Green Deal (COM (2019) 640) specifically opens up for the possibility of introducing carbon boarder adjustments to counteract the risk of carbon leakage.

As evident from Table 1, there is considerable potential for trade-related measures for climate action to be considered in future NDC updates, especially among the major emitters (e.g. the USA, China, and EU) and exporters of embodied carbon (e.g. China) (cf. Brandi 2017). Clearly, acknowledgment of potential leakage, the need to limit the outsourcing of carbon intensive production to other countries, and climate mitigation policies' relation to trade are largely missing in the NDCs.

A key objection to highlighting trade issues at the UNFCCC is the perception that these should be dealt with at the WTO (based on interviews with three UNFCCC negotiators COP22 2016). Another concern is that efforts to address emission outsourcing at the UNFCCC may lead to distortions in international trade (e.g. regarding issues such as intellectual property rights, fossil fuel subsidies, renewable energy exports) and could complicate policy-making further (interview with developing country negotiator, COP 22 2016; Chan et al. 2016; Whalley 2011).

\subsection{Carbon outsourcing in the Kyoto Protocol}

The risk of carbon leakage offsetting part of the effect of achieving NDC targets has been highlighted above. This section looks deeper into the dynamics and effects of carbon leakage. We investigate how countries' balance of emissions embodied in trade (BEET) and technology-adjusted balance of emissions embodied in trade (TBEET) developed during the period 2000-2014, which largely overlaps with the period when the KP was in place and fully covers the first commitment period 2008-2012. It therefore serves as an example of the potential impact of carbon outsourcing on climate targets. By including a large part of the time between when the protocol was signed and the first commitment period, and two years after the first commitment period ended, we also capture possible effects of

\footnotetext{
7 An example are free allocations for specific sectors under the EU Emissions Trading Scheme to prevent carbon leakage.
} 

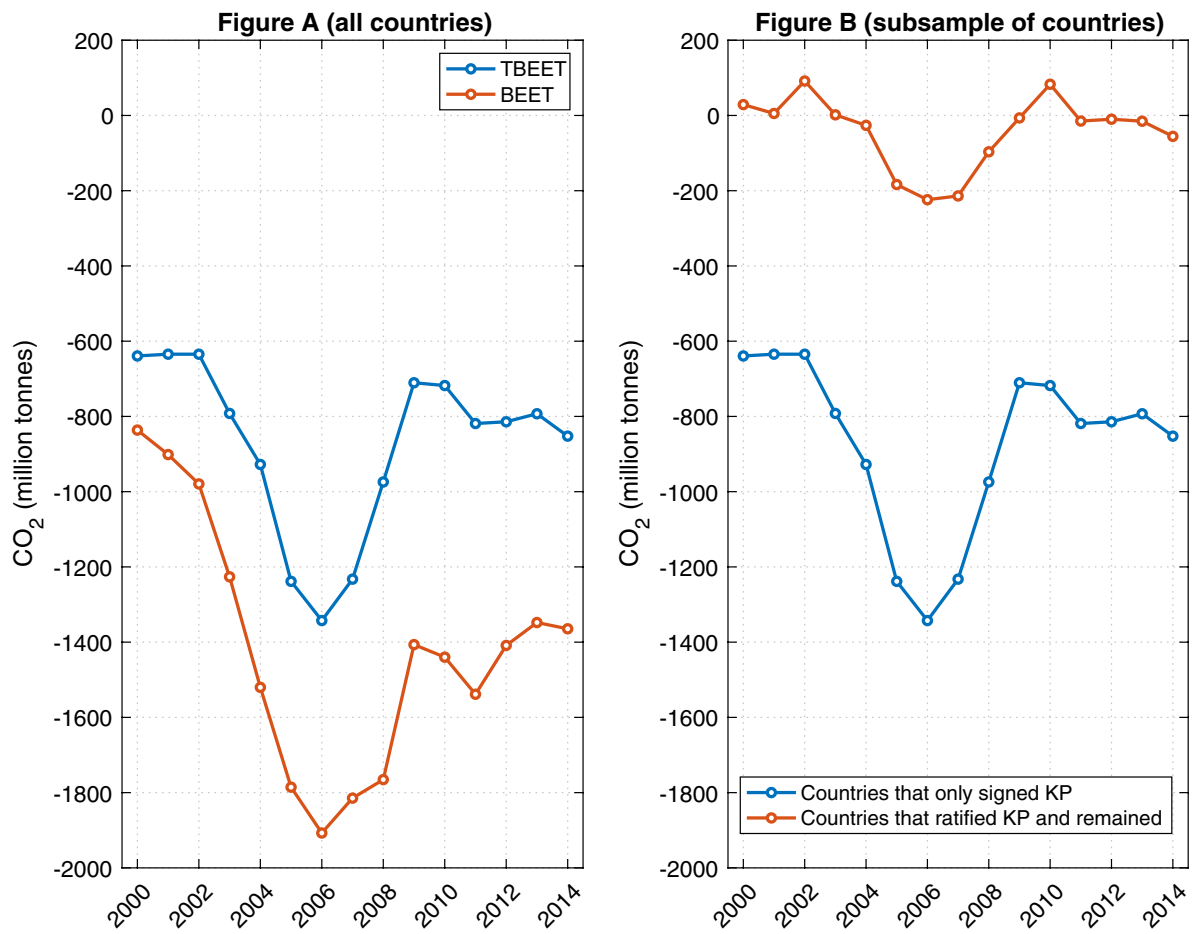

Fig. 1 Conventional balance of emissions embodied in trade (BEET) and technology-adjusted emission trade balance (TBEET) for the countries that signed the Kyoto Protocol (KP) 2000-2014. a All countries signing KP and b Comparing the TBEET of countries only signing KP and those that ratified and remained within the KP (Note: b "Countries that only signed KP" group consists of all countries in the sample except BRA, CHN, IDN, IND, KOR, MEX, TUR, TWN; "Countries that ratified and remained" group consist of all countries except BRA, CHN, IDN, IND, KOR, MEX, TUR, TWN, USA, CAN (see Supplementary Information 6 for the country codes).)

policies being implemented in advance of the commitment period and possible delayed effects. All developed countries signed the KP, but the USA never ratified it and Canada later withdrew from its commitments.

\subsubsection{Carbon leakage and binding targets}

Figure 1a shows the development of the traditional, BEET, and the technology-adjusted balance of emissions embodied in trade, TBEET, for the group of countries with Kyoto targets, including the USA and Canada (see Supplementary Information for tabularized and country-specific results). In short, a positive TBEET is an indication of carbon insourcing, while a negative value indicates carbon outsourcing. Figure 1a shows that the group as a whole was a net carbon outsourcer throughout the observed period and had a substantially lower TBEET in 2014 as compared to 2000. The pattern of TBEET is similar to that of traditional BEET, but differs in that its decrease was less pronounced. Either way, these results provide evidence for increasing carbon outsourcing during the period.

Figure 1b, on the other hand, shows the development of the TBEET indicators only, but where the USA and Canada are disregarded in order to focus on the countries that remained 


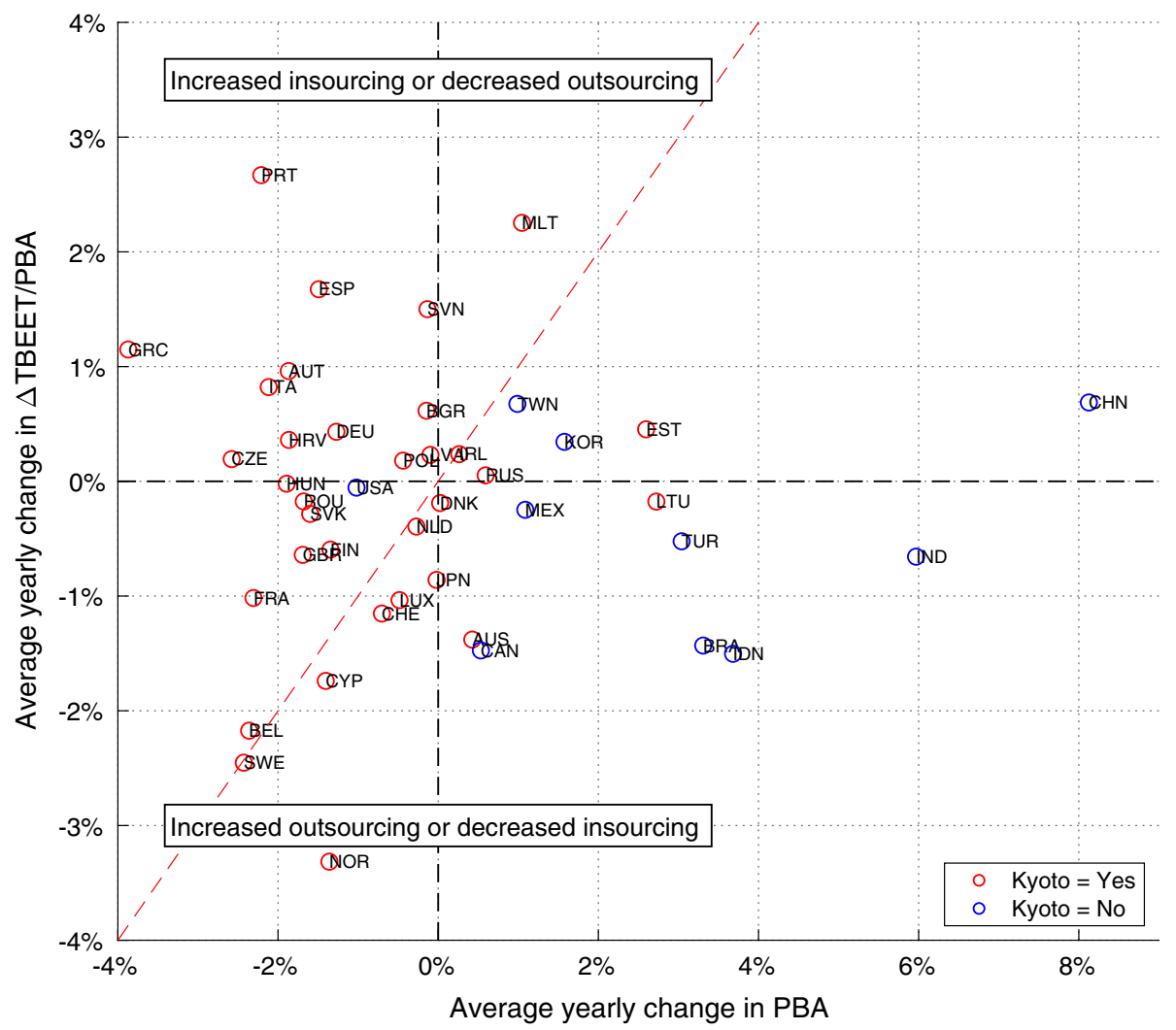

Fig. 2 Individual country performance on production-based emissions (PBA) and carbon outsourcing (TBEET). Note: Average yearly change in $\triangle$ TBEET/PBA (vertical axis) is calculated: $\frac{1}{2} \sum_{t}^{n}\left(\mathrm{TBEET}_{t}-\mathrm{TBEET}_{t-1}\right) / \mathrm{PBA}_{t-1}$. Average yearly change in PBA (horizontal axis) is calculated as: $\frac{1}{n} \sum_{t}^{h}\left(\mathrm{PBA}_{t}-\mathrm{PBA}_{t-1}\right) / \mathrm{PBA}_{t-1}$ with points to the left of the vertical line indicating emission decreases and the points to the right indicating emission increases over time

in the treaty throughout the stated period. The comparison shows that the negative trend displayed in Fig. 1a is largely driven by the countries that did not ratify the KP or remained a part of it. In contrast, the group of countries that remained in the KP were either comparatively minor net outsourcers of emissions ( 9 years during the observed period) or even net carbon insourcers ( 6 of the 15 regarded years). While changing back and forth between an overall negative and positive balance of TBEET in the countries that remained in the $\mathrm{KP}$, the trend between 2000 and 2014 is declining, which is an indication that at least part of the reported emissions reductions was offset by changes in trade patterns. Therefore, the trend towards increasing carbon outsourcing and, consequently, a potential undermining of climate mitigation policies under the KP is evident from the TBEET for the countries that remained in the treaty.

As apparent from Fig. 1a and b, the observed outsourcing is largely driven by the USA, which never ratified the KP. Depending on the respective year, the group of countries that maintained their climate mitigation commitments actually either were minor net outsourcers on aggregate or even appeared as insourcers of $\mathrm{CO}_{2}$. This allows for the optimistic interpretation that binding emission targets do not necessarily lead to carbon outsourcing. 
It is not the countries with the toughest emission reduction commitments that outsource emissions. There is a slightly falling trend in the TBEET among countries that stayed in the KP, which offset part-but not all—of the aggregate emission reductions. Collectively, countries that signed, ratified, and stayed within the KP reduced their domestic emissions by 10 per cent during the period. Roughly one-quarter of this reduction-i.e. 2.5 percentage points—was offset by changes in their TBEET.

\subsubsection{Individual countries' risk of carbon leakage}

Examining the performance of individual countries, Fig. 2 displays each country's average yearly change in production-based emissions (PBA) between 2000 and 2014 on the horizontal line and change in TBEET over the same years on the vertical line (divided by PBA in the corresponding year for comparability). All underlying data and discussion around the uncertainties of the analysis can be found in Supplementary Information.

Countries that appear to the right of the vertical line have increased PBA emissions and those to the left have decreased PBA emissions. Countries below the horizontal line with negative values of $\triangle$ TBEET/PBA had lower TBEET in 2014 compared with 2000, indicating an increase in carbon outsourcing or decrease in carbon insourcing. The colours of the circles indicate the status in relation to the KP commitments. A red circle indicates binding Kyoto emission targets, and the fact that the country signed, ratified, and stayed committed to the protocol throughout the investigated period. A blue circle indicates that the country either had no binding commitments according to the protocol, that it did not ratify it (i.e. the USA), or did not remain within it (i.e. Canada).

Since the figure shows relative changes in TBEET, we cannot tell whether a negative trend indicates increased outsourcing or decreased insourcing of emissions from this graph itself. This depends on the absolute value of TBEET and may be derived from Supplementary Information. A positive and declining TBEET indicates a case of decreasing insourcing, whereas a negative and declining TBEET characterizes increased outsourcing. Of course, it is also possible that a country went from insourcing to outsourcing, or vice versa. For our purposes here, however, the change as such is of interest rather than absolute levels in order to identify trends during the period of previous binding climate mitigation targets (i.e. within the KP).

We analyze a total of 43 countries of which 33 were committed to the KP and 10 were not, either not ratifying, i.e. the USA, or without binding targets, e.g. China. The dotted diagonal line indicates where the improvement/deterioration of TBEET is equal to the decrease/increase in PBA.

Countries in the upper left box reduced their PBA while improving TBEET; hence, the reported reductions in production-based emissions were not undermined by increased outsourcing or decreased insourcing of emissions via trade. Countries in the lower left box reduced their PBA but at the same time showed deteriorating TBEET; hence, the reported reductions in production-based emissions were at least partly undermined by increased outsourcing/decreased insourcing. For countries to the left of the dotted red line, the reduction in PBA was larger than the deterioration of TBEET; hence, at least part of the production-based emissions reduction was "real" as it has not been undermined by increased emission outsourcing or decreased insourcing. For countries to the right of the dotted red line, TBEET deteriorated more than PBA improved; hence, reported production-based emissions reductions were completely undermined by increased outsourcing/decreased insourcing. 
Countries in the upper right box increased their PBA but also improved TBEET. For countries to the left of the dotted red line, the improvement of TBEET was larger than the increase in PBA, implying increased insourcing or decreased outsourcing of emissions that more than outweighed the increase in production-based emissions. To the right of that line, PBA increased more than the improvement of TBEET, implying that the increase in production-based emissions was only partly outweighed by decreased outsourcing/ increased insourcing. Countries in the lower right box worsened their performance in both dimensions: increasing PBA while at the same time increasing outsourcing or decreasing insourcing of emissions.

The figure thus shows that approximately half of the countries ( 21 of 43 , left side of the dotted line in Fig. 2) in our sample improved their overall climate performance over the period. Twenty of these were countries with binding Kyoto commitments. The USA was the only country without such a commitment that improved its overall performance. Twelve countries improved in both dimensions, while nine (including the USA) improved more in one dimension than they deteriorated in the other.

On the other hand, around 40 per cent (13 of 33, coloured in red to the right of the dotted line in Fig. 2) of the sampled countries that were committed to Kyoto targets worsened their overall performance over the period. Increased production-based emissions, increased outsourcing/decreased insourcing, or both drove this negative development. While we cannot-of course-infer direct causation between the Kyoto targets and outsourcing, this finding is nonetheless important.

For the ten countries in our sample that did not ratify or remain within the KP (blue circles in Fig. 2), the pattern is clear. All countries apart from the USA increased their production-based emissions and six of them also increased carbon outsourcing or decreased insourcing. For instance, Brazil increased its TBEET deficit ninefold, India's TBEET declined fivefold while the USA showed a slight decrease in TBEET between 2000 and 2014. The other three countries (China, South Korea, and Taiwan) without binding Kyoto targets increased their PBA, and although part of this increase was due to increased carbon insourcing, improving TBEET did not outweigh the entire increase in production-based emissions.

\section{Discussion and concluding remarks}

The interlinkage between international trade and climate change remains an important issue under the Paris Agreement and the consideration of trade elements in the UNFCCC remains insufficient (Brandi 2017). Our analysis demonstrates how countries have largely neglected trade-related issues in the current NDC submissions (see Table 1). Although NDCs are not necessarily representative of countries' trade policies, the analysis of NDCs highlights the neglect of international trade in general and carbon outsourcing specifically. Future rounds of NDCs need to provide more clarity and coherence when it comes to efforts to reduce the risks of carbon leakage. This could include: more clarity on whether countries with absolute targets outsource their carbon to countries with relative targets; more clarity and room for discussion on the international effects of countries' consumption behaviour on global emissions; more clarity in reflecting on the potential negative external effects of carbon emission's decoupling from economic progress. Finally, there needs to be more coordination on policies that could reduce the risk of carbon leakage. While the qualitative analysis highlights the lack of acknowledgement of potential carbon outsourcing 
under the Paris Agreement, the quantitative part investigates the potential consequences of this by highlighting the trend of emission outsourcing patterns under a previous treaty aimed to combat climate change.

The quantitative part of this study ascertains that carbon outsourcing was a real issue during the KP period (cf. Aichele and Felbermayr 2015; Peters and Hertwich 2008). However, unlike the previous research, our study also demonstrates that carbon outsourcing from developed to developing countries was dominated by countries that did not implement the Kyoto Protocol. Future studies should further explore the factors accounting for this trend. Given that global carbon outsourcing in the period 1995-2014 was dominated by the USA outsourcing to China (see also Baumert et al. 2019), it is problematic that the USA, once again, announced its withdrawal from a global climate agreement. This makes it imperative that trade and climate regimes are further interconnected and able to assess the potential risks of countries' production-based carbon reductions being offset by carbon leakage to others.

This is not to say that all countries should aim at minimizing carbon outsourcing. Carbon outsourcing is not in itself necessarily negative (Jiborn et al. 2018; Baumert et al. 2019). Industries that move to new countries provide the receiving countries with new revenue and jobs, and countries also differ with regard to access to low carbon energy resources and other relevant factors. If outsourcing means that energy intensive production is increasingly located in countries that are well endowed with low carbon energy resources, it can actually result in a more efficient distribution of international production for global emissions. If production is increasingly outsourced in the opposite direction, the result is less carbon efficient global production.

One aspect we do emphasize is the need for multiple monitoring approaches. The limitations of territorial monitoring of carbon emissions have been made explicit for some time (Peters 2008; Davis and Caldeira 2010). In contrast to consumption-based accounting, which is traditionally considered the main alternative to PBA, TBEET adequately accounts for emissions transfers that can be characterized as carbon outsourcing via the structure and magnitude of international trade. Hence, complementing PBA with TBEET would add a relevant perspective and constitute a major step forward to monitoring climate mitigation efforts, for example during global stocktakes (Milkoreit and Haapala 2018).

Continuous and more sophisticated monitoring of emission outsourcing would improve transparency and knowledge concerning GHG transfers across economic sectors and countries. Moreover, it would allow policy-makers to assess to what extent domestic emission reductions may result in increases elsewhere. It would also enable a comparison between different sectors within countries, providing a useful overview of how different sectors compare on a global scale with regard to carbon efficiency.

In general, having multiple monitoring techniques would provide a more comprehensive picture of the effects of countries' climate actions and policies and may thus potentially lead to more effective climate policies (Steininger et al. 2015). However, this would necessitate further negotiations on the suitable choice of climate monitoring approaches, which many countries would be reluctant to encourage. In the worst case, it may also foster parallel agreements based on different accounting systems, which would further add to the complexity of global climate governance (Betsill et al. 2015).

Despite these limitations, countries like Sweden and the UK have to some extent addressed the issue of carbon outsourcing in their domestic climate agendas (cf. Swedish Parliament's Cross-Party Environmental Goals Committee 2016:21, 47; Barrett et al. 2013), albeit not in their NDCs. Future rounds of NDC reporting need to provide momentum on countries that have either started considering their emissions responsibility abroad 
or intend to invoke measures to (potentially) reduce carbon leakage. Discussions on how to address this need to take place both at the domestic and intergovernmental level. The UNFCCC and other forums like the WTO need to provide suitable venues where countries can coordinate their efforts and find common ways to implement and monitor effects that national climate actions can have abroad.

Acknowledgments This study was funded by a grant from the Swedish Energy Agency.

Funding Open access funding provided by Lund University.

Open Access This article is licensed under a Creative Commons Attribution 4.0 International License, which permits use, sharing, adaptation, distribution and reproduction in any medium or format, as long as you give appropriate credit to the original author(s) and the source, provide a link to the Creative Commons licence, and indicate if changes were made. The images or other third party material in this article are included in the article's Creative Commons licence, unless indicated otherwise in a credit line to the material. If material is not included in the article's Creative Commons licence and your intended use is not permitted by statutory regulation or exceeds the permitted use, you will need to obtain permission directly from the copyright holder. To view a copy of this licence, visit http://creativecommons.org/licenses/by/4.0/.

\section{References}

Aichele, R., \& Felbermayr, G. (2015). Kyoto and carbon leakage: an empirical analysis of the carbon content of bilateral trade. Review of Economics \& Statistics, 97(1), 104-115. https://doi.org/10.1162/ REST_a_00438.

Arroyo-Currás, T., Bauer, N., Kriegler, E., Schwanitz, V. J., Luderer, G., Aboumahboub, T., et al. (2015). Carbon leakage in a fragmented climate regime: the dynamic response of global energy markets. Technological Forecasting and Social Change, 90, 192-203. https://doi.org/10.1016/j.techfore.2013.10.002.

Bacchus, J. (2016). Global rules for mutually supportive and reinforcing trade and climate regimes. Geneva. http://www3.weforum.org/docs/E15/WEF_Climate_Change_POP.pdf.

Barrett, J., Peters, G., Wiedmann, T., Scott, K., Lenzen, M., Roelich, K., et al. (2013). Consumptionbased GHG emission accounting: a UK case study. Climate Policy, 13(4), 451-470. https://doi. org/10.1080/14693062.2013.788858.

Baumert, N., Kander, A., Jiborn, M., Kulionis, V., \& Nielsen, T. D. (2019). Global outsourcing of carbon emissions 1995-2009: a reassessment. Environmental Science and Policy, 92, 228-236. https://doi. org/10.1016/j.envsci.2018.10.010.

Betsill, M, Dubash N.K., Paterson M, van Asselt H, Vihma A, \& Winkler H. (2015). Building productive links between the UNFCCC and the broader global climate governance landscape. Global Environmental Politics, 15 (2), 1-10. https://doi.org/10.1162/GLEP_a_00294.

Bhagwati, J., \& Mavroidis, P. C. (2007). Is action against US exports for failure to sign Kyoto Protocol WTO-legal? World Trade Review, 6(2), 299-310. https://doi.org/10.1017/S1474745607003291.

Brandi, C (2017). Trade elements in countries' climate contributions under the Paris agreement. International Centre for Trade and Sustainable Development (ICTSD) Issue Paper.

Chan, S., Brandi, C., \& Bauer, S. (2016). Aligning transnational climate action with international climate governance: the road from Paris. Review of European, Comparative \& International Environmental Law, 25(2), 238-247. https://doi.org/10.1111/reel.12168.

Charlery, L., \& Trærup, S. L. M. (2019). The nexus between nationally determined contributions and technology needs assessments: a global analysis. Climate Policy, 19(2), 189-205. https://doi. org/10.1080/14693062.2018.1479957.

Corsatea T.D., Lindner S., Arto, I., Román, M.V., Rueda-Cantuche J.M., Velázquez Afonso A., Amores A.F., Neuwahl F. (2019); World Input-Output Database Environmental Accounts. Update 2000-2016, Publications Office of the European Union, Luxembourg, 2019, ISBN 978-92-79-64439-9, https://doi. org/10.2791/947252, JRC116234.

Davis, S. J., and Caldeira K. (2010). Consumption-based accounting of CO2 emissions. PNAS 107 (12), 5687LP-5692LP https://doi.org/10.1073/pnas.0906974107.

Edward, J. B., Kaffine, D., \& Yonezawa, H. (2015). Optimal environmental border adjustments under the general agreement on tariffs and trade. SSRN Electronic Journal. https://doi.org/10.2139/ssrn.27484 46. 
Harris, P. G., \& Symons, J. (2013). Norm conflict in climate governance: greenhouse gas accounting and the problem of consumption. Global Environmental Politics, 13(1), 9-29. https://doi.org/10.1162/ GLEP_a_00151.

Jakob, M., \& Marschinski, R. (2012). Interpreting trade-related CO2 emission transfers. Nature Climate Change, 3, 19. https://doi.org/10.1038/nclimate1630.

Jakob, M., Marschinski, R., \& Hübler, M. (2013). Between a rock and a hard place: a trade-theory analysis of leakage under production- and consumption-based policies. Environmental and Resource Economics, 56(1), 47-72. https://doi.org/10.1007/s10640-013-9638-y.

Jakob, M., Steckel, J. C., \& Edenhofer, O. (2014). Consumption-versus production-based emission policies. Annual Review of Resource Economics, 6(1), 297-318. https://doi.org/10.1146/annurev-resource100913-012342.

Jiborn, M., Kander, A., Kulionis, V., Nielsen, H., \& Moran, D. D. (2018). Decoupling or delusion? Measuring emissions displacement in Foreign Trade. Global Environmental Change, 49, 27-34. https://doi. org/10.1016/j.gloenvcha.2017.12.006.

Jiborn, M., Kulionis, V., \& Kander, A. (2020). Consumption versus technology: Drivers of global carbon emissions 2000-2014. Energies, 13(2), 339. https://doi.org/10.3390/en13020339.

Kander, A., Jiborn, M., Moran D. D., \& Wiedmann T. O. (2015). National greenhouse-gas accounting for eEffective climate policy on International Trade. Nature Climate Change, 5, 431. https://doi. org/10.1038/nclimate2555.

Ladly, S. D. (2012). Border carbon adjustments, WTO-law and the principle of common but differentiated responsibilities. International Environmental Agreements: Politics, Law and Economics, 12(1), 63-84. https://doi.org/10.1007/s10784-011-9153-y.

Mehling, M. A., van Asselt, H., Das, K., \& Droege, S. (2018). Beat protectionism and emissions at a stroke. Nature. https://doi.org/10.1038/d41586-018-05708-7.

Milkoreit, M., \& Haapala, K. (2018). The global stocktake: design lessons for a new review and ambition mechanism in the international climate regime. International Environmental Agreements: Politics, Law and Economics, 19(1), 89-106. https://doi.org/10.1007/s10784-018-9425-X.

Muller, B., \& Michaelowa, A. (2019). How to operationalize accounting under Article 6 market mechanisms of the Paris Agreement. Climate Policy, 19(7), 812-819. https://doi.org/10.1080/14693062.2019.15998 03

Parry, M. L., Canziani, O. F., Palutikof, J. P., van der Linden, P. J., \& Hanson, C. E. (Eds.). (2007). Contribution of Working Group II to the Fourth Assessment Report of the Intergovernmental Panel on Climate Change. Cambridge: Cambridge University Press.

Pauw, P. W., Cassanmagnano, D., Mbeva, K., Hein, J., Guarin, A., Brandi, C., et al. (2016). NDC Explorer.. https://doi.org/10.23661/ndc_explorer_2017_2.0.

Peters, G. P. (2008). From production-based to consumption-based National emission inventories. Ecological Economics, 65(1), 13-23. https://doi.org/10.1016/j.ecolecon.2007.10.014.

Peters, G. P., \& Hertwich, E. G. (2008). $\mathrm{CO}_{2}$ embodied in international trade with implications for global climate policy. Environmental Science \& Technology, 42(5), 1401-1407. https://doi.org/10.1021/es072 $023 \mathrm{k}$.

Peters, G. P., Minx, J. C., Weber, C. L., \& Edenhofer, O. (2011). Growth in emission transfers via international trade from 1990 to 2008. PNAS, 108(21), 8903-8908. https://doi.org/10.1073/pnas.1006388108.

Stadler, K., Wood, R., Bulavskaya, T., Södersten, C.-J., Simas, M., Schmidt, S., et al. (2018). EXIOBASE 3: developing a time series of detailed environmentally extended multi-regional input-output tables. Journal of Industrial Ecology, 22(3), 502-515. https://doi.org/10.1111/jiec.12715.

Steininger, K. W., Lininger, C., Meyer, L. H., Muñoz, P., \& Schinko, T. (2015). Multiple carbon accounting to support just and effective climate policies. Nature Climate Change, 6, 35-41. https://doi. org/10.1038/nclimate2867.

Timmer, M. P., Dietzenbacher, E., Los, B., Stehrer, R., \& Vries, G. J. (2015). An illustrated user guide to the World input-output database: the case of global automotive production. Review of International Economics, 23(3), 575-605. https://doi.org/10.1111/roie.12178.

Tørstad, V., \& Sælen, H. (2018). Fairness in the climate negotiations: What explains variation in parties' expressed conceptions? Climate Policy, 18(5), 642-654. https://doi.org/10.1080/14693062.2017.13413 72.

Whalley, J. (2011). What role for trade in a post-2012 global climate policy regime. The World Economy, 34(11), 1844-1862. https://doi.org/10.1111/j.1467-9701.2011.01422.x.

Wiedmann, T. (2009). A review of recent multi-region input-output models used for consumption-based emission and resource accounting. Ecological Economics, 69(2), 211-222. https://doi.org/10.1016/j. ecolecon.2009.08.026. 
Winkler, H., Mantlana, B., \& Letete, T. (2017). Transparency of action and support in the Paris Agreement. Climate Policy, 17(7), 853-872. https://doi.org/10.1080/14693062.2017.1302918.

Wood, R., Stadler, K., Simas, M., Bulavskaya, T., Giljum, S., Lutter, S., et al. (2018). Growth in environmental footprints and environmental impacts embodied in trade: resource efficiency indicators from EXIOBASE3. Journal of Industrial Ecology, 22(3), 553-564. https://doi.org/10.1111/jiec.12735.

Wyckoff, A. W, \& Roop J. M. (1994). The embodiment of carbon in imports of manufactured products: implications for International Agreements on Greenhouse Gas Emissions. Energy Policy, 22 (3), 187194. https://econpapers.repec.org/RePEc:eee:enepol:v:22:y:1994:i:3:p:187-194.

Publisher's Note Springer Nature remains neutral with regard to jurisdictional claims in published maps and institutional affiliations. 